\title{
Sessile Serrated Adenoma of the Appendix and Perforated Cecal Lymphoma in a Nonagenarian on Novel Anticoagulant Undergoing Emergent Surgery: The Challenges, Decision Making and Management of a Rare Case
}

\author{
Saptarshi Biswas ${ }^{\mathrm{a}, \mathrm{d}}$, Shekhar Gogna ${ }^{\mathrm{b}}$, Jeffrey Uselman ${ }^{\mathrm{c}}$
}

\begin{abstract}
A 92-year-old male with significant past medical history of atrial fibrillation, congenital heart disease, coronary artery disease (CAD), deep vein thrombosis (DVT), hyperlipidemia (HLD), hypertension (HTN), myocardial infarction (MI), and peripheral vascular disease presented to emergency department (ED) with shortness of breath and right sided chest pain. He was hypotensive and tachycardic with right upper and lower quadrant tenderness on clinical examination. Initial pulmonary embolism (PE) protocol CT scan was negative for pulmonary embolism but revealed a large $13 \mathrm{~cm}$ mass in right lower quadrant (RLQ) with adjacent free peritoneal air and fluid, suspicious for perforated cecal neoplasm or abscess. He received activated prothrombin complex concentrate (PCC) for emergent reversal of apixaban and taken emergently for exploratory laparotomy, where he underwent an extended right hemicolectomy with end ileostomy and a long Hartmann's. The ileocecal lesion was large and extended from the terminal ileum to almost the hepatic flexure. Histopathology revealed high-grade B-cell lymphoma involving the terminal ileum, cecum, ascending colon, appendix, and mesenteric lymph nodes. The specimen also contained a serrated sessile appendicular adenoma. We discuss urgent/emergent surgeries in nonagenarians with multiple comorbidities on novel oral anticoagulant (NOAC) as well as the indications of palliative surgery in these patient groups. We also discuss synchronous serrated adenoma along with the perforated high-grade lymphoma in the same patient.
\end{abstract}

Keywords: Perforation; Cecal lymphoma; Serrated appendicular adenoma; NOAC

Manuscript submitted June 4, 2018, accepted July 24, 2018

a Department of Trauma and Acute Care Surgery, Forbes Regional Hospital, Allegheny Health Network, Monroeville, PA 15146, USA

bDepartment of General Surgery, Westchester University Medical Center, Valhalla, NY, USA

${ }^{c}$ Lake Erie College of Osteopathic Medicine (LECOM), Erie, PA, USA

${ }^{\mathrm{d} C o r r e s p o n d i n g ~ A u t h o r: ~ S a p t a r s h i ~ B i s w a s, ~ D e p a r t m e n t ~ o f ~ T r a u m a ~ a n d ~ A c u t e ~}$ Care Surgery, Forbes Regional Hospital, Allegheny Health Network, Monroeville, PA 15146, USA. Email: spartabiswas@gmail.com

doi: https://doi.org/10.14740/jmc3124w

\section{Introduction}

Lymphomas are hematologic malignancies with a wide variety of histologic subtypes and a broad spectrum of clinical behavior, aggressiveness, and prognosis [1]. It is the sixth most common cause of cancer-related death in the United States [2]. Colorectal lymphomas account for 15 to $20 \%$ of gastrointestinal lymphomas and it predominantly affects males between the sixth and seventh decade of life. The cecum is the most common location for colorectal lymphomas [3]. There are established guidelines for the management of lymphomas including palliative care. Palliative surgical procedures can be performed to relieve obstruction, manage perforation and aim to improve other symptoms. In this case report we describe the emergent management of perforated lymphoma and incidental finding of serrated sessile polyps in the appendix of our patient. The appendiceal polyps often display morphologic similarities to their colorectal counterparts. Some authors believe that the molecular events leading to appendiceal neoplasm are similar to those in colorectal carcinoma as these appendiceal polyps also follow "adenoma-carcinoma" sequence [4]. The significance of this incidental lesion in our patient is, however, not known. We also discuss the management of said surgical candidates who are on novel anticoagulants (NOAC) and undergoing emergent surgery as was the case with our patient, who was on apixaban.

\section{Case Report}

We present a case report of a 92-year-old male with significant past medical history of atrial fibrillation, RBBB, congenital heart disease, coronary artery disease (CAD), ischemic cardiomyopathy deep vein thrombosis (DVT), hyperlipidemia (HLD), hypertension (HTN), myocardial infarction (MI), osteoarthritis, prostate cancer, popliteal aneurysm, iliac aneurysm and peripheral vascular disease. He was on apixaban for atrial fibrillation. He presented to emergency department (ED) with shortness of breath and pain on right side of the chest. His vitals on presentation were as follows; temperature of 36.6 ${ }^{\circ} \mathrm{C}$, HR $114 / \mathrm{min}$, BP 93/62 mm Hg, RR 18/min, and saturating at $92 \%$ on $2 \mathrm{~L}$ nasal canula (NC). Upon physical examination 


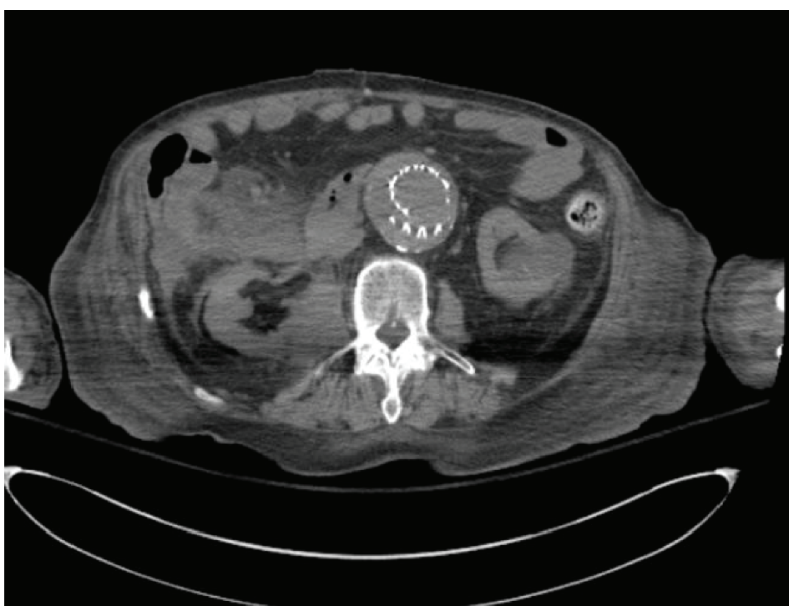

Figure 1. Perforated mass in right iliac fossa.

the patient appeared well nourished, alert and oriented. Lungs were clear to auscultation bilaterally. Cardiovascular examination revealed tachycardia with an irregularly irregular rate. His abdomen was doughy and mildly distended. Upon palpation he endorsed right upper and right lower quadrant tenderness without rebound or peritoneal signs. Computed tomography (CT) scan of the abdomen revealed a large $13 \mathrm{~cm}$ mass in right lower quadrant with adjacent free peritoneal air and fluid which was suspicious for perforated cecal neoplasm or abscess (Fig. 1).

The patient was admitted to the surgical service where he underwent an exploratory laparotomy, extended right hemicolectomy with end ileostomy and a long Hartmann's. Our patient was on apixaban for atrial fibrillation which made the procedure very "oozy". Operative findings revealed a perforated tumor in cecum and terminal ileum measuring approximately $10-14 \mathrm{~cm}$ and was found to be stuck to the adjoining mesentery and omentum, extending up to the hepatic flexure. Incidentally, the patient was found to have a second malignancy in the appendix which was classified as a sessile serrated adenoma (Fig. 2).

The patient was on pressors throughout the case to maintain an adequate MAP for tissue perfusion and received multi-

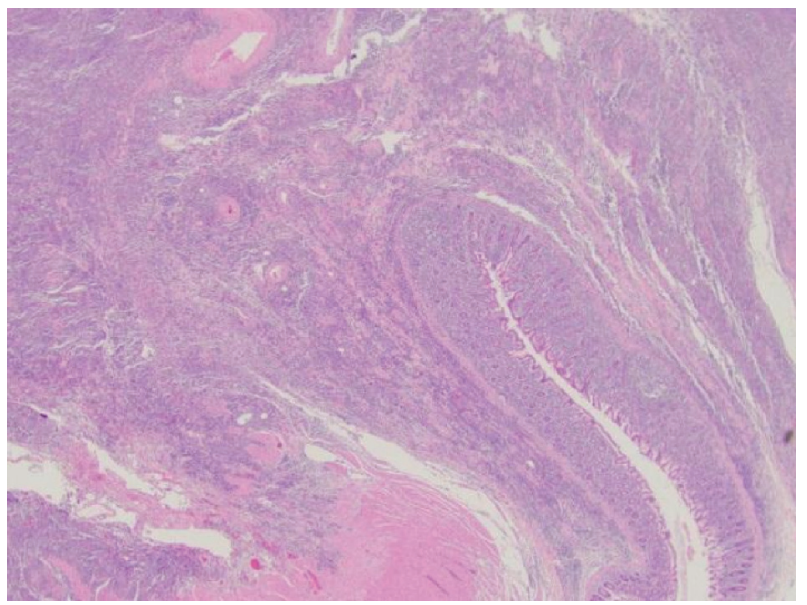

Figure 2. Histopathological slide showing sessile serrated adenoma.

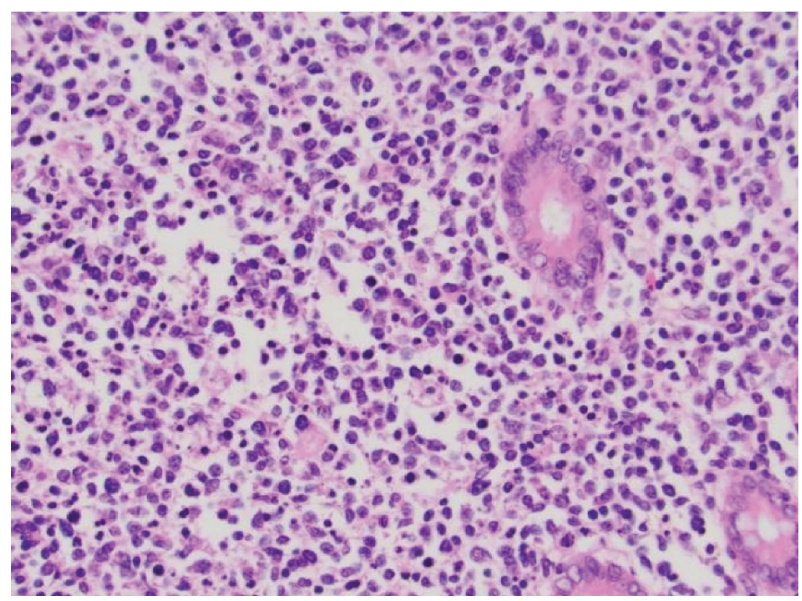

Figure 3. Histopathological slide showing diffuse large B cell lymphoma, IHC positive for CD10 and CD20.

ple boluses and transfusions of blood products. The estimated estimated blood loss (EBL) was over $1 \mathrm{~L}$. His postoperative course in ICU was eventful for hemodynamic instability requiring levophed and milrinone drips, postoperative non-STelevation myocardial infarction (NSTEMI) and AKI. Oncology, cardiology, nephrology and palliative services were on board in his care. He was successfully extubated on postoperative day 3. On postoperative day 8, a CT scan performed for fever workup showed perihepatic fluid collection which was drained by Interventional Radiology. The Yueh catheter placed through the intercostal approach put out $1,150 \mathrm{~mL}$. On day 15 he developed fascial dehiscence. He was taken back to the OR for re-exploration, abdominal washout, revision of the end ileostomy and fascial closure. He remained stable subsequently and 2 days following the last surgery was sent to the floor. The oncology team had suggested PET scan but opined that he was not a good candidate for chemotherapy. The patient was very clear that he did not want any aggressive escalation in his care given his age and comorbid conditions and after discussion with his family made himself comfort measures. Patient was discharged to skilled nursing facility in a stable condition.

Histopathology revealed high-grade B-cell lymphoma with a germinal center immunohistochemistry that showed a high proliferative fraction involving the terminal ileum, cecum, ascending colon, appendix, and mesenteric lymph nodes. The immunohistochemical staining (IHC) was positive for CD10, CD20, and Bcl-6 (Fig. 3).

\section{Discussion}

Dawson et al established the criteria for the diagnosis of primary colorectal lymphomas in 1961 [5] (Table 1).

There are five histological subtypes of B-cell lymphoma according to the WHO classification. These include: extranodal marginal lymphoma, follicular lymphoma, mantle cell lymphoma, diffuse large B-cell lymphoma, and Burkitt's lymphoma [6]. In our case, the location of tumor was in the cecum. The literature shows that primary intestinal lymphoma most 
Table 1. Criteria for Diagnosing Colorectal Lymphoma

1 No enlarged superficial lymph nodes on first patient encounter

2 White cell counts and bone marrow biopsy in normal range

3 No mediastinal lymphadenopathy on chest radiographs

4 Only regional nodes are affected by the disease at laparotomy

5 Liver and the spleen are free of tumor

commonly involves the ileocecal region, preferentially in the cecum due to the high proportion of lymphoid tissue found here [7]. Colonic lymphomas are more frequent in males and rarely seen in children [8]. Cecal lymphomas can present with varying symptoms such as abdominal pain, anorexia, weight loss, diarrhea, ileus, lower gastrointestinal bleeding, and intussusception $[9,10]$.

Our patient presented with a perforated cecal lymphoma, thus adding to the few case reports dealing with acute perforation as the initial presentation of a cecal lymphoma. Perforations are potentially life threatening and often lead to a complicated course of increased morbidity from sepsis, multiorgan failure, prolonged hospital stay, wound healing failures and even mortality [11]. Studies have shown gastrointestinal lymphomas complicated by perforations are reported to have inferior outcomes [12-14]. In a large retrospective study using Mayo Clinic Lymphoma data base, R Vaidya et al found that diffuse, large B cell lymphoma (DLBL) was the most common lymphoma that perforated. And this risk was significantly higher with B cell aggressive compared to the B cell indolent variety and $\mathrm{T}$ cell post transplant lymphoproliferative group (PTLD). Vaidya et al [11] mentioned that in their study $60 \%$ of the patients with perforations had died by the time of the last follow-up. Etiologies of perforations are attributed to acute inflammation and/or tumor necrosis [15], radiation enteritis [12], diverticulitis after chemotherapy [12], neutropenic colitis [16] procedure related [17], severe $C$. difficile colitis [16], cytomegalovirus enteritis [16] and Ogilvie syndrome [16].

Radiological findings on CT scan are often non-specific and comprise of mucosal nodularities, areas of bowel wall thickening, and submucosal masses. Colonoscopy biopsies may be needed to establish the tissue diagnosis. Currently, laparotomy and surgical resection are the only reliable means of definitive diagnosis [18].

While the role of surgery in the treatment of gastrointestinal lymphoma is debatable, performing surgery may provide invaluable prognostic information, including extensiveness of the tumor and its' stage. Two definitive indications for surgery exist in patients with cecal lymphoma: obstruction and perforation [19]. O. Bairey et al showed the rate of spontaneous perforation was high (5 out of 17 patients), he recommended to perform elective hemicolectomy to prevent such complication [7]. There is a general consensus that surgery does offer the definitive chance of a cure.

Interestingly enough, on histopathological examination our patient had additional findings of a sessile serrated polyp in appendix. Sessile serrated adenoma/polyp (SSA/P) is a colonic polyp that can arise in the appendix [20]. Studies have proven that SSA/P is considered a precursor of microsatellite unstable colorectal carcinoma [21]. There are two pathways of carcinogenesis in colon. Conventional adenomas lead to carcinomas in $60 \%$ of cases by a suppressor pathway, leading to microsatellite stable carcinomas. In about $35 \%$ of cases, carcinomas arise along the "serrated pathway" which develops from the precursor lesion known as the sessile serrated adenoma (also referred to as the sessile serrated polyp) [22]. Incidental finding of serrated sessile polyp in the nonagenarian patient seen in our case report suggests that he was probably at very high risk for colon cancer.

The aging of the general population has lead to an increase in the number of patients amongst the octa and nonagenarian age groups requiring surgical treatment in emergency setting. Colorectal neoplasia in patients over 90 years of age represents an ethical dilemma for surgeons, especially when the disease process is advanced and complicated by obstruction and/or perforation. The surgeon often has to weigh the benefits and risks associated with frailty, polypharmacy and comorbidities prior to submitting the patient to surgery [23]. We need to have a clear and precise discussion with the patient and their relatives about treatment options with palliative or curative intent. Surgery is the key curative treatment for colon and rectal neoplasm. Palliative surgery offers valuable options to increase quality of life of patients. When deciding on the course of treatment the primary objective of the acute care surgeon should be maintenance of the independent status, life expectancy and quality of life for the elderly patient.

We cannot deem an elderly octa or nonagenarian unfit for surgery based on chronological age. A great variation in individual health status with increasing age exists and physiological/biological age does not always reflect chronological age. Literature review has shown a considerable number of elderly patients will continue to live with good functions and excellent quality of life after emergency surgery [24-27]. Many authors reported that emergency surgery for CRC in patients over 90 years of age can be performed safely [28-31].

It is known that patients with a high burden of comorbidity at the time of cancer diagnosis have a higher mortality rate [32]. The effect of comorbidity on outcomes in oncological surgery may be confounded by factors such as age [33], performance status [33, 34], and tumor-related factors [35]. Comorbidity is a complicated area of study because its assessment is multi-dimensional, requiring consideration of a range of conditions as well as their prognostic impact. To capture comorbidity more quantitatively, index systems have been developed that generate an overall score on the basis of a list of medical conditions with weighted or graded severity values [36].

Generally, emergency abdominal procedures are associated with increased morbidity and mortality rates, particularly for frail elderly patients. For the ACS surgeon proper patient selection is paramount. Patients over 80 s of age admitted to an ACS service, have a higher risk of postoperative complications, with increased morbidity and mortality rates [37, 38], despite significant strides in perioperative care, surgical techniques and advancements in anesthesiology and ICU.

Kenig in a prospective study conducted on 184 patients $\geq 65$ years of age, evaluated the diagnostic accuracy of the Vulnerable Elderly Survey (VES-13), Triage Risk Screening Tool (TRST), Geriatric-8 (G8), Groningen Frailty Index (GFI), 
Rockwood, Balducci score; the outcome measured using these tests were sensitive and specific values that predict 30-day postoperative outcome. He concluded that it is possible to safely and efficiently perform screening tests for frailty in older patients who are potential candidates for emergency surgery. The VES-13 survey was determined to be the best screening instrument for its highest sensitivity and negative predictive value both for postoperative mortality and morbidity, by asking simply questions about independent living [39].

Gomes et al [40] in a retrospective observational longitudinal study conducted on a population of patients aged $>$ 80 years, compared the predictive values of the Physiological and Operative Severity Score for the EnUmeration of Mortality and Morbidity (POSSUM), the Portsmouth (P) POSSUM, the ColoRectal (CR)-POSSUM, and CR-BHOM in colorectal surgical mortality and morbidity in elective and emergency setting. Gomes concluded that CR POSSUM was the best predictor of surgical mortality and morbidity; POSSUM and P POSSUM underestimated surgical mortality and morbidity and CR BHOM overestimated surgical mortality, but none of the scores showed sufficient discriminatory power to have clinical application value. Gomes concluded that the elderly patient's health status and not surgery type is primary indicator mainly responsible of surgical outcomes [40].

The American Anesthesiology Association (ASA) classification is determined on admission and has shown to be predictive of complications and mortality. Recent retrospective studies [41] demonstrated that high ASA class is associated with high mortality following emergency surgery. Careful selection and preoperative evaluation of the patient maximizes surgical outcomes.

In emergency situations, one-stage surgery is the best choice, if feasible. However, often a two-stage surgery is indicated in case of florid peritonitis, hemodynamic instability and malnourished patients due to the high risk of anastomotic breakdown [42]. Decompressive colostomy or ileostomy may be necessary as bridge to elective surgery in operable patients, or as palliative procedure, in advanced neoplastic disease and peritoneal carcinomatosis.

Length of hospital stay is longer for patients aged over 90 than for younger patients and emergency surgical intervention is a potential promoter of permanent disability. In fact, discharge is often to long care facilities, with high costs for the public health. The incidence of Post Operative Delirium (POD) is high for both emergency and elective surgery, leading to an increase in hospital stay and perioperative mortality [43, 44].

Intraoperatively we observed lot of raw surface oozing which can be attributed to the use of apixaban to a large extent. The number of elderly patients taking anticoagulants and antiplatelet agents has been steadily increasing in USA [45]. Anticoagulation using vitamin $\mathrm{K}$ antagonists (VKA) is the conventional treatment and prevention of thromboembolic disorders. The main constraints of VKA's are their need for close monitoring and extensive drug interactions. Hence, these are gradually being replaced by an emerging class of drugs termed NOACs which are now approved for the treatment of venous thromboembolic disease and for the prevention of embolism in nonvalvular atrial fibrillation [46]. Despite more favourable pharmacokinetic profile of NOAC compared to VKA the risk of bleeding complications prevail and mainly apparent in the emergency setting. According to published studies (e.g. RECOVER study of dabigatran [47], EINSTEIN study of rivaroxaban [48] and AMPLIFY study of apixaban [49]) the rate of major bleeding complications with NOACs range from 2.1 to $3.6 \% /$ year [50]. Some authors have added risk score such as HAS-BLED [51-53] or HEMORR2HAGES [52, 53] as contributing factors. These score include patient-related variables such as hypertension, renal function and age. The type of surgical intervention being performed also plays a major role.

Protocols that are commonly in use for NOACs are mostly for routine perioperative period [54]. Currently no consensual guidelines for management of patients on NOACs achieved in emergent surgery settings. Knowledge and integration of the patient's coagulation status is the key to proper decision making $[52,55-57]$. Management of bleeding during emergency surgery is challenging due to the absence of specific antidotes. NOACs have relatively short half-lives (7 - $17 \mathrm{~h})$ and so supportive care and withholding further doses are sufficient management for many patients [58]. In most cases waiting two half-lives (upto $24 \mathrm{~h}$ ) may reduce the drug levels enough for safe surgical intervention [59]. However these may not be applicable with patients with peritonitis or with hepatic and/or renal failure. In some cases, further management will depend on plasma drug concentration and require administration of procoagulant drugs. Plasma drug concentration tests are not easily accessible at all institutes.

Gastric lavage with activated charcoal can prevent absorbtion and reduce the plasma concentration of NOAC when the last administration was within a few hours [59]. Hemofiltration with charcoal filters may not be useful in an emergent surgery situation. For renally excreted drugs like dabigatran hemodialysis is an alternate method of elimination. For actively bleeding patients resuscitation is often carried out in the lines of ATLS often with activation of massive transfusion. Procoagulant drugs are often added at the start of resuscitation. Prothrombin complex concentrate (PCC) at a dose of 25 - $50 \mathrm{U} /$ $\mathrm{kg}$ body weight, which can be repeated at the failure of the first dose [56, 57, 59-61]. PCC is readily available, easily prepared and quick to administer without excess volume, and without any increased risk of disease transmission $[52,60]$. Fresh frozen plasma can be used but adds a volume load in the elderly patient groups with compromised cardiac function and takes 30 min to thaw.

We need to weigh the thrombotic risk of the patient's cardiovascular disease and the bleeding risk of the recent surgery prior to starting the NOAC. NOACs can be started $6-8 \mathrm{~h}$ after the surgical intervention in patients with low hemorrhagic risk. In patients with low thrombotic risk NOACs can be started 48 - $72 \mathrm{~h}$ after the procedure. In high risk cases starting a bridging therapy is advisable. Most authors recommend starting lowmolecular-weight heparin (LMWH) in the immediate postoperative period, after $6-8 \mathrm{~h}$, and resume NOAC after $48 \mathrm{~h}$ and always $12 \mathrm{~h}$ after the last dose of LMWH [55, 61, 62]. Sometimes the commencement of NOACS have to be delayed after surgery e.g. NPO status, postoperative nausea and vomiting, ileus, gastric and bowel resection and/or anticipated need for future procedures [63]. Parenteral anticoagulants should be used until these issues resolve. 


\section{Conclusions}

Non-Hodgkin's lymphoma (NHL) of the ileocecal area is rare but remains amongst the recognized differential diagnosis of pathology that presents in right lower quadrant. Chemotherapy, biological therapy, radiotherapy and hematopoietic stem cell transplantation are the mainstay of treatment of lymphomas. Emergency surgery is often used as a last resort in treating symptomatic disease limited to an organ. Emergent surgery for NHL in nonagenarian patients presents as a special challenge due to this age group having multiple other comorbidities and risk factors, novel anticoagulants use being one of them. Ultimately, the careful consideration of the risks versus benefits, and clinical judgment of the surgeon is of paramount importance when discussing surgery in emergent settings with the patient and family.

\section{Acknowledgments}

We thank William Leukhardt MD, for his active involvement in the perioperative clinical management of the patient, and Lyndsey Kreutzer for her pharmacy input in the perioperative period.

\section{Conflict of Interest}

None.

\section{References}

1. Quayle FJ, Lowney JK. Colorectal lymphoma. Clin Colon Rectal Surg. 2006;19(2):49-53.

2. American Cancer Society. Cancer facts and figures. Atlanta, GA: American Cancer Society; 2005.

3. Wong MT, Eu KW. Primary colorectal lymphomas. Colorectal Dis. 2006;8(7):586-591.

4. Yantiss RK, Panczykowski A, Misdraji J, Hahn HP, Odze RD, Rennert H, Chen YT. A comprehensive study of nondysplastic and dysplastic serrated polyps of the vermiform appendix. Am J Surg Pathol. 2007;31(11):17421753.

5. Dawson IM, Cornes JS, Morson BC. Primary malignant lymphoid tumours of the intestinal tract. Report of 37 cases with a study of factors influencing prognosis. Br J Surg. 1961;49:80-89.

6. Harris NL, Jaffe ES, Diebold J, Flandrin G, Muller-Hermelink HK, Vardiman J. Lymphoma classification - from controversy to consensus: the R.E.A.L. and WHO Classification of lymphoid neoplasms. Ann Oncol. 2000;(Suppl 1):3-10.

7. Bairey O, Ruchlemer R, Shoilberg O. Non Hodgkins lymphoma of colon. IMAJ. 2006;8:832-836.

8. Gonzalez QH, Heslin MJ, Davila-Cervantes A, AlvarezTostado J, de los Monteros AE, Shore G, Vickers SM. Primary colonic lymphoma. Am Surg. 2008;74(3):214-216.
9. Pervez H, Shaikh M, Potti A, Mehdi SA. Uncommon presentations of non-Hodgkin's lymphoma: case 3. Primary renal lymphoma. J Clin Oncol. 2003;21(3):567569.

10. Jayabackthan L, Murgi SB, Graham S, Kini RG. A rare case of primary lymphoma of the caecum presenting as intussusception. J Lab Physicians. 2013;5(2):118-120.

11. Vaidya R, Habermann TM, Donohue JH, Ristow KM, Maurer MJ, Macon WR, Colgan JP, et al. Bowel perforation in intestinal lymphoma: incidence and clinical features. Ann Oncol. 2013;24(9):2439-2443.

12. Amer MH, el-Akkad S. Gastrointestinal lymphoma in adults: clinical features and management of 300 cases. Gastroenterology. 1994;106(4):846-858.

13. Gou HF, Zang J, Jiang M, Yang Y, Cao D, Chen XC. Clinical prognostic analysis of 116 patients with primary intestinal non-Hodgkin lymphoma. Med Oncol. 2012;29(1):227-234.

14. Kako S, Oshima K, Sato M, Terasako K, Okuda S, Nakasone H, Yamazaki R, et al. Clinical outcome in patients with small-intestinal non-Hodgkin lymphoma. Leuk Lymphoma. 2009;50(10):1618-1624.

15. Domizio P, Owen RA, Shepherd NA, Talbot IC, Norton AJ. Primary lymphoma of the small intestine. A clinicopathological study of 119 cases. Am J Surg Pathol. 1993;17(5):429-442.

16. d'Amore F, Brincker H, Gronbaek K, Thorling K, Pedersen M, Jensen MK, Andersen E, et al. Non-Hodgkin's lymphoma of the gastrointestinal tract: a population-based analysis of incidence, geographic distribution, clinicopathologic presentation features, and prognosis. Danish Lymphoma Study Group. J Clin Oncol. 1994;12(8):16731684.

17. Otter R, Bieger R, Kluin PM, Hermans J, Willemze R. Primary gastrointestinal non-Hodgkin's lymphoma in a population-based registry. Br J Cancer. 1989;60(5):745750.

18. Stanojevic GZ, Nestorovic MD, Brankovic BR, Stojanovic MP, Jovanovic MM, Radojkovic MD. Primary colorectal lymphoma: An overview. World J Gastrointest Oncol. 2011;3(1):14-18.

19. Weledji EP, Orock GE. Surgery for Non-Hodgkin's lymphoma. Oncol Rev. 2015;9(1):274.

20. Rubio CA. Serrated adenomas of the appendix. J Clin Pathol. 2004;57(9):946-949.

21. Bordacahar B, Barret M, Terris B, Dhooge M, Dreanic J, Prat F, Coriat R, et al. Sessile serrated adenoma: from identification to resection. Dig Liver Dis. 2015;47(2):95102.

22. Snover DC. Update on the serrated pathway to colorectal carcinoma. Hum Pathol. 2011;42(1):1-10.

23. De Simone Belinda, Catena Fausto. Emergency surgery for colorectal cancer in patients aged over 90 years: review of the recent literature. Journal of Tumor. 2015;4(1):349353.

24. Fried LP, Tangen CM, Walston J, Newman AB, Hirsch C, Gottdiener J, Seeman T, et al. Frailty in older adults: evidence for a phenotype. J Gerontol A Biol Sci Med Sci. 2001;56(3):M146-156. 
25. Merani S, Payne J, Padwal RS, Hudson D, Widder SL, Khadaroo RG. Predictors of in-hospital mortality and complications in very elderly patients undergoing emergency surgery. World J Emerg Surg. 2014;9:43.

26. Papamichael D, Audisio R, Horiot JC, Glimelius B, Sastre J, Mitry E, Van Cutsem E, et al. Treatment of the elderly colorectal cancer patient: SIOG expert recommendations. Ann Oncol. 2009;20(1):5-16.

27. Neuman HB, O'Connor ES, Weiss J, Loconte NK, Greenblatt DY, Greenberg CC, Smith MA. Surgical treatment of colon cancer in patients aged 80 years and older: analysis of 31,574 patients in the SEER-Medicare database. Cancer. 2013;119(3):639-647.

28. Basili G, Lorenzetti L, Biondi G, Preziuso E, Angrisano C, Carnesecchi P, Roberto E, et al. Colorectal cancer in the elderly. Is there a role for safe and curative surgery? ANZ J Surg. 2008;78(6):466-470.

29. Formisano V, Di Muria A, Connola G, Cione G, Falco L, De Angelis CP, Angrisani L. Our experience in the management of obstructing colorectal cancer. Ann Ital Chir. 2014;85(6):563-568.

30. Bouassida M, Charrada H, Chtourou MF, Hamzaoui L, Mighri MM, Sassi S, Azzouz MM, et al. Surgery for colorectal cancer in elderly patients: how could we improve early outcomes? J Clin Diagn Res. 2015;9(5):PC04-08.

31. Catena F, Pasqualini E, Tonini V, Avanzolini A, Campione O. Emergency surgery for patients with colorectal cancer over 90 years of age. Hepatogastroenterology. 2002;49(48):1538-1539.

32. Piccirillo JF, Tierney RM, Costas I, Grove L, Spitznagel EL, Jr. Prognostic importance of comorbidity in a hospital-based cancer registry. JAMA. 2004;291(20):24412447.

33. Koroukian SM, Murray P, Madigan E. Comorbidity, disability, and geriatric syndromes in elderly cancer patients receiving home health care. J Clin Oncol. 2006;24(15):2304-2310.

34. Extermann M, Overcash J, Lyman GH, Parr J, Balducci L. Comorbidity and functional status are independent in older cancer patients. J Clin Oncol. 1998;16(4):15821587.

35. Read WL, Tierney RM, Page NC, Costas I, Govindan R, Spitznagel EL, Piccirillo JF. Differential prognostic impact of comorbidity. J Clin Oncol. 2004;22(15):30993103.

36. Javier Gallego Plazas, Elena Asensio, Juan C. Navalon, Inmaculada Lozano, Jose M. Navarro, Guillermo Ricote, Montse Olcina, et al. Colorectal cancer surgery in extreme elderly population. Journal of Cancer Therapy. 2015;6:12-20.

37. van de Velde CJ, Boelens PG, Tanis PJ, Espin E, Mroczkowski P, Naredi P, Pahlman L, et al. Experts reviews of the multidisciplinary consensus conference colon and rectal cancer 2012: science, opinions and experiences from the experts of surgery. Eur J Surg Oncol. 2014;40(4):454468.

38. Boyd JB, Bradford B, Jr., Watne AL. Operative risk factors of colon resection in the elderly. Ann Surg. 1980;192(6):743-746.
39. Kenig J, Zychiewicz B, Olszewska U, Barczynski M, Nowak W. Six screening instruments for frailty in older patients qualified for emergency abdominal surgery. Arch Gerontol Geriatr. 2015;61(3):437-442.

40. Gomes A, Rocha R, Marinho R, Sousa M, Pignatelli N, Carneiro C, Nunes V. Colorectal surgical mortality and morbidity in elderly patients: comparison of POSSUM, P-POSSUM, CR-POSSUM, and CR-BHOM. Int J Colorectal Dis. 2015;30(2):173-179.

41. Soreide K, Desserud KF. Emergency surgery in the elderly: the balance between function, frailty, fatality and futility. Scand J Trauma Resusc Emerg Med. 2015;23:10.

42. Gundogdu RH, Yasar U, Ersoy PE, Ergul E, Isikoglu S, Erhan A. Effects of preoperative nutritional support on colonic anastomotic healing in malnourished rats. Ulus Cerrahi Derg. 2015;31(3):113-117.

43. Ansaloni L, Catena F, Chattat R, Fortuna D, Franceschi C, Mascitti P, Melotti RM. Risk factors and incidence of postoperative delirium in elderly patients after elective and emergency surgery. Br J Surg. 2010;97(2):273-280.

44. Raats JW, van Eijsden WA, Crolla RM, Steyerberg EW, van der Laan L. Risk factors and outcomes for postoperative delirium after major surgery in elderly patients. PLoS One. 2015;10(8):e0136071.

45. Maxwell CA, Miller RS, Dietrich MS, Mion LC, Minnick A. The aging of America: a comprehensive look at over 25,000 geriatric trauma admissions to United States hospitals. Am Surg. 2015;81(6):630-636.

46. Enriquez A, Lip GY, Baranchuk A. Anticoagulation reversal in the era of the non-vitamin K oral anticoagulants. Europace. 2016;18(7):955-964.

47. Schulman S, Kearon C, Kakkar AK, Mismetti P, Schellong S, Eriksson H, Baanstra D, et al. Dabigatran versus warfarin in the treatment of acute venous thromboembolism. N Engl J Med. 2009;361(24):2342-2352.

48. Investigators $\mathrm{E}$, Bauersachs $\mathrm{R}$, Berkowitz $\mathrm{SD}$, Brenner B, Buller HR, Decousus H, Gallus AS, et al. Oral rivaroxaban for symptomatic venous thromboembolism. N Engl J Med. 2010;363(26):2499-2510.

49. Agnelli G, Buller HR, Cohen A, Curto M, Gallus AS, Johnson M, Masiukiewicz U, et al. Oral apixaban for the treatment of acute venous thromboembolism. N Engl J Med. 2013;369(9):799-808.

50. Levy JH, Szlam F, Wolberg AS, Winkler A. Clinical use of the activated partial thromboplastin time and prothrombin time for screening: a review of the literature and current guidelines for testing. Clin Lab Med. 2014;34(3):453477.

51. Garcia-Fernandez A, Marin F, Roldan V, Galcera-Jornet E, Martinez-Martinez JG, Valdes M, Sogorb F, et al. The HAS-BLED score predicts long-term major bleeding and death in anticoagulated non-valvular atrial fibrillation patients undergoing electrical cardioversion. Int J Cardiol. 2016;217:42-48.

52. Dincq AS, Lessire S, Douxfils J, Dogne JM, Gourdin M, Mullier F. Management of non-vitamin K antagonist oral anticoagulants in the perioperative setting. Biomed Res Int. 2014;2014:385014.

53. Fauchier L, Chaize G, Gaudin AF, Vainchtock A, Rushton- 
Smith SK, Cotte FE. Predictive ability of HAS-BLED, HEMORR2HAGES, and ATRIA bleeding risk scores in patients with atrial fibrillation. A French nationwide cross-sectional study. Int J Cardiol. 2016;217:85-91.

54. Faraoni D, Samama CM, Ranucci M, Dietrich W, Levy JH. Perioperative management of patients receiving new oral anticoagulants: an international survey. Clin Lab Med. 2014;34(3):637-654.

55. Weitz JI, Pollack CV, Jr. Practical management of bleeding in patients receiving non-vitamin $\mathrm{K}$ antagonist oral anticoagulants. Thromb Haemost. 2015;114(6):11131126.

56. Pernod G, Albaladejo P, Godier A, Samama CM, Susen S, Gruel Y, Blais N, et al. Management of major bleeding complications and emergency surgery in patients on longterm treatment with direct oral anticoagulants, thrombin or factor-Xa inhibitors: proposals of the working group on perioperative haemostasis (GIHP) - March 2013. Arch Cardiovasc Dis. 2013;106(6-7):382-393.

57. Sie P, Samama CM, Godier A, Rosencher N, Steib A, Llau JV, Van der Linden P, et al. Surgery and invasive procedures in patients on long-term treatment with direct oral anticoagulants: thrombin or factor-Xa inhibitors. Recommendations of the Working Group on Perioperative Haemostasis and the French Study Group on Thrombosis and
Haemostasis. Arch Cardiovasc Dis. 2011;104(12):669676.

58. Pinho-Gomes AC, Hague A, Ghosh J. Management of novel oral anticoagulants in emergency and trauma surgery. Surgeon. 2016;14(4):234-239.

59. Jorge Pereira, Luis Filipe Pinheiro. The patient needs emergency surgery and is under treatment with non-vitamin $\mathrm{K}$ antagonist oral anticoagulants: what shall we do? Clinics in Surgery. 2017;2:Article 1366.

60. Makris M. Prothrombin complex concentrate for nonvitamin K oral anticoagulant reversal: good enough for now? J Thromb Haemost. 2014;12(9):1425-1427.

61. Faraoni D, Levy JH, Albaladejo P, Samama CM, Groupe d'Interet en Hemostase P. Updates in the perioperative and emergency management of non-vitamin $\mathrm{K}$ antagonist oral anticoagulants. Crit Care. 2015;19:203.

62. Tran H, Joseph J, Young L, McRae S, Curnow J, Nandurkar $\mathrm{H}$, Wood $\mathrm{P}$, et al. New oral anticoagulants: a practical guide on prescription, laboratory testing and peri-procedural/bleeding management. Australasian Society of Thrombosis and Haemostasis. Intern Med J. 2014;44(6):525-536.

63. Anderson M, Hassell KL, Trujillo TC, Wolfe B. When patients on target-specific oral anticoagulants need surgery. Cleve Clin J Med. 2014;81(10):629-639. 